\title{
An Experimental Investigation on The Properties of Concrete by Partial Replacement of Fine Aggregate with Demolition Waste
}

\author{
B. Srinivasulu ${ }^{1}, \mathrm{~K}$. Mohammed Rasheed ${ }^{2}$ \\ ${ }^{* 1}$ M.Tech Student, Department of Civil Engineering, Chiranjeevi Reddy Institution of Engineering and \\ Technology, Anantapuram, Andhra pradesh , India \\ ${ }^{2}$ Assistant Professor, Department of Civil Engineering, Chiranjeevi Reddy Institute of Engineering and \\ Technology, Anantapuram, Andhra Pradesh, India
}

\begin{abstract}
Concrete is the most widely used as construction materials in the world. In fact, concrete is used in virtually everything and there are still no substitutes are available for many of its application. Without concrete, the community and society today could not exist. Therefore, lots of researchers and engineers are doing the research of the aggregate sources. All these research as alternative sources for the replacement of the natural aggregates in producing concrete in the various future construction works. In that concept we had made the research on the fine aggregate replacement in concrete with the construction and demolition waste. The project explains about the properties of materials used in concrete, mechanical and transport properties of the concrete.
\end{abstract} Keywords: Demolition, Aggregate, Virtually.

\section{INTRODUCTION}

In Asia, the construction activities are extremely emerging. Parallel to that, one of the main problems in urban areas is the vast amount of construction and demolition waste produced everyday. In many population growth and developing countries, construction and demolition waste often had been disposed incorrectly. Since an obligation of searching the solutions, recycling of the waste is the profitable and appropriate alternative that will improve the construction method. The utilization waste materials will help to avoid several environmental or health damages, reduce the exploration of natural resources, and increase the lifetime of the landfill. The abandoned concrete waste products are generated in a significant amount during the production process or the demolition of the buildings. It has causes a large land required storing it and consequence in land pollution. These problems will spend a lot of money. In order to make sure the continuously of crushed aggregates supply, the recycling or reuse the concrete waste as an alternate source as an aggregate replacement.

\subsection{Objective}

The main objectives of this project are described as follows:

a) To determine the characteristics of the recycled fine aggregate.

b) To determine hardened concrete properties containing in recycled fine aggregate concrete.

c) To determine transportation properties of recycled fine aggregate concrete.

d) To identify the optimum proportion for replacement the natural fine aggregate with recycled fine aggregate in the concrete. 


\subsection{Scope of Study}

The concrete waste was crushed to fine aggregate with the maximum aggregate size of $4.75 \mathrm{~mm}$. Then, the concrete design mix proportion was prepared where the batching of the concrete material was done by weight. Mix proportioning was based on the water cement ratio (water/cement) and the density of the concrete is $2400 \mathrm{~kg} / \mathrm{m}^{3}$. The scope of this study is the replacement of natural fine aggregate (sand) with recycled fine aggregate. The ratio of sand replaced to recycled fine aggregate are $100: 0 \%$ as control, $80: 20 \%$, 50:50\%, 20:80\% and 0:100\%.

\section{LITERATURE REVIEW}

Cement concrete is environmentally clean construction material, produced from the local raw materials: aggregates (sand and gravel), cement and water. This is universal construction material used for the construction of various buildings and constructions, as well as for the production of construction parts. The choice of construction materials is always determined by quality and price. Both, concrete's quality, as well as price, largely depends on the raw materials used in the production. In concrete's production process it is important to reduce costs in any technological stage as much as possible. However, the quality parameters of the final product have to fulfill the defined limits. One of the ways to reduce the production costs is to replace the natural aggregates with the ones, produced from buildings' demolition waste. Moreover, from ecological point of view, concrete is an ideal material, where it is possible to integrate construction and demolition waste during then manufacturing process.

Demolition and construction waste consists of the following waste materials: reinforced concrete, concrete, bricks, tiles, glass, wood and other materials, obtained during the demolition of the buildings.
Larger amount of buildings' demolition waste consists of concrete and ceramics. Main composition of this waste is shown in Fig. 1.

There are several reasons why the amount of construction and demolition waste is increasing worldwide:

$\checkmark$ There are a lot of buildings that are not suitable for exploitation, therefore they have to be rehabilitated or demolished;

$\checkmark$ Buildings, even if they are suitable for the exploitation (for instance old factories, farm buildings etc.), lose their functionality, their purpose changes and finally they are demolished (Fig. 1).

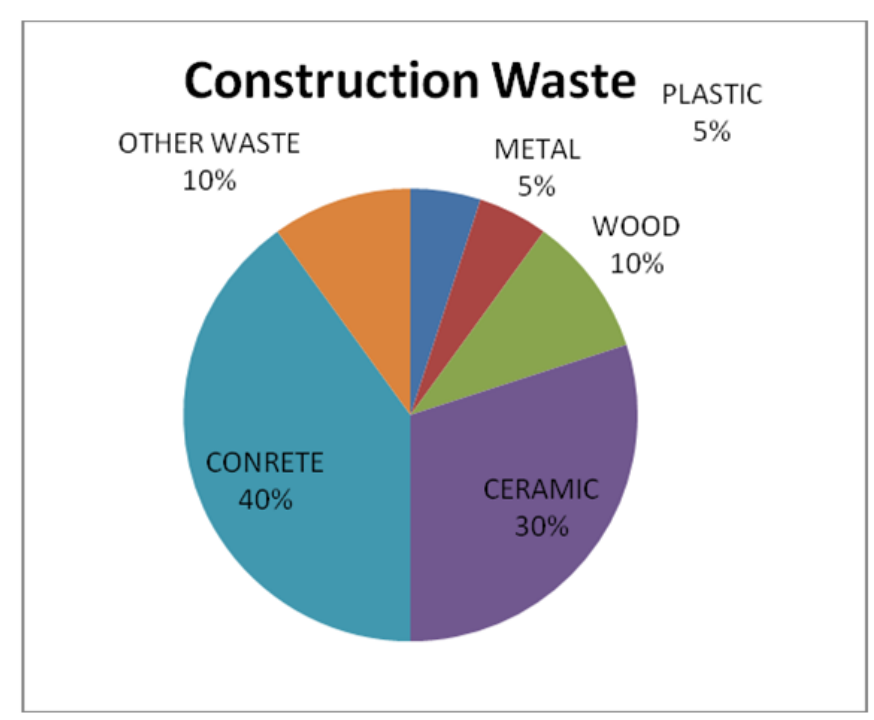

\section{MATERIALS AND MIX PROPORTIONING}

\subsection{Materials used:}

\subsubsection{Cement:}

Cement as it commonly known, is a mixture of compounds made by burning limestone and clay together at very high temperature ranging from 1400 to 1600 c. although there are other cements for special purposes, this project will focus solely on Portland cement and its properties. 


\subsubsection{Water:}

Water is the key ingredient, which when mixed with cement, forms a paste that binds the aggregates together. The water causes the hardening of concrete through a process called hydration. Hydration is a chemical reaction in which the major compounds in cement form chemical bonds with water molecules and become hydrates or hydration products. The water needs to be pure in order to prevent side reactions from occurring, which may weaken the concrete or otherwise interfere with the hydration process. The role of water is important because the water to cement ration is the most critical factor in the production of "perfect" concrete. Too much water reduces concrete strength, while too little will make the concrete unworkable. Concrete needs to be workable so that it may be consolidated and shaped in to different forms (I.e. walls, domes, etc). Because concrete must be both strong and workable, a careful balance of the cement to water ratio is required when making concrete. Portable water is considered satisfactory for mixing concrete. The water should be colourless and free from any smell. The presence of chlorides and sulphates are injurious to reinforcing bars as they may be corroded.

\subsection{Aggregates:}

Aggregates are chemically inert, solid bodies held together by the cement. Aggregates come in various shapes, sizes and materials ranging from fine particles of sand to large course rocks. Because cement is the most expensive ingredient in making concrete, it is desirable to minimize the amount of cement used. 70 to $80 \%$ of the volume of concrete is aggregate keeping the cost of the concrete low. The selection of aggregate is determined, impart by the desired characteristics of the concrete. For example, the density of the aggregate determines the density of concrete. Soft, porous aggregates can result in weak concrete with low wear resistance, while using hard aggregates can make strong concrete with a high resistance to abrasion.

Aggregates should be clean, hard and strong. The aggregate is usually washed to remove any dust, silt, clay, organic matter or other impurities that would interfere with the bonding reaction with the cement paste. It is then separated in to various sizes by passing the materials through a series of screens with different size openings.

\subsubsection{Fine Aggregates:}

The fine aggregate locally was used in this investigation. The aggregate was sieved through IS sieve. The fine aggregate or sand may be natural or crushed. It may be available in a riverbed or in a quarry. The sizes of sand particles vary from a maximum of $4.75 \mathrm{~mm}$ down to $150 \mathrm{micron}$ i.e. $0.150 \mathrm{~mm}$. Good sand must contain all the particles with in the above range that is and it should be graded sand. The sand may be sieved through the Indian standards sieves: $4.75 \mathrm{~mm}, 2.36 \mathrm{~mm}, 1.18 \mathrm{~mm}$, 600-micron, 300 micron and 150 microns. The sand may be classified as VERY COURSE (ZONE 1), MEDIUM COURSE (ZONE 2), COURSE (ZONE 3) and FINE (ZONE 4) depending upon its grain size distribution.

\subsubsection{Coarse Aggregate:}

The course aggregate may be natural or crushed gravel. It may have a maximum size of $20 \mathrm{~mm}$ down to $4.75 \mathrm{~mm}$ and should be graded. It should be clean, and free from dust and other impurities. It should be stored separately from sand or lime etc. on a hard surface. If necessary, the aggregate may be washed and dried for 72 hours before use. Moist or wet aggregate should be used in construction. The aggregate consists of over $75 \%$ of concrete mix. 
Therefore save cement by using clean and graded aggregate having proper shape and size

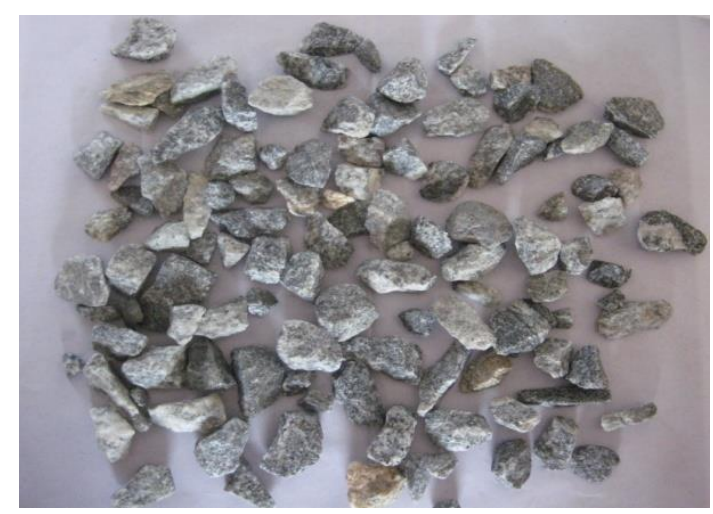

\subsection{Recycled Aggregate :}

The building and demolition waste are taken and crushed to separate fine and coarse materials. Then the aggregates are sent to the batching plant and washed to remove the fines, and then they are separated by sieving. In our project we had been using the recycled fine aggregate. The aggregates passing through $4.75 \mathrm{~mm}$ sieve and retained on 90 micron are taken.

\section{Properties of Recycled Fine aggregates}

\begin{tabular}{|l|l|l|}
\hline A. S.no & B. Particulars & C. Results \\
\hline D. 1 & E. Type & $\begin{array}{l}\text { F. Building } \\
\text { Waste }\end{array}$ \\
\hline G. 2 & H. Specific Gravity & I. 2.72 \\
\hline J. 3 & K. Water absorption & L. $4 \%$ \\
\hline M. 4 & N. Fineness modulus & O. 3.06 \\
\hline P. 5 & Q. Grading & R. Zone II \\
\hline S. 6 & T. Density & U. \\
\hline
\end{tabular}

In the properties of the recycled aggregates when they are compared with the natural fine aggregates the Specific gravity has been increased, water absorption is also increased due to the large amount of fines present in the recycled fine aggregate. So the grading had been changed from the zone -III to the zone-II. The fineness modulus is also been changed and the density of the recycled fine aggregate has been increased.

So we must make into the consideration most probably the water absorption of the $\mathrm{R} \mathrm{F} \mathrm{A}$ and add the amount of water in more percentage into the concrete

levels of water reduction possible allow major increases in strength to be obtained.

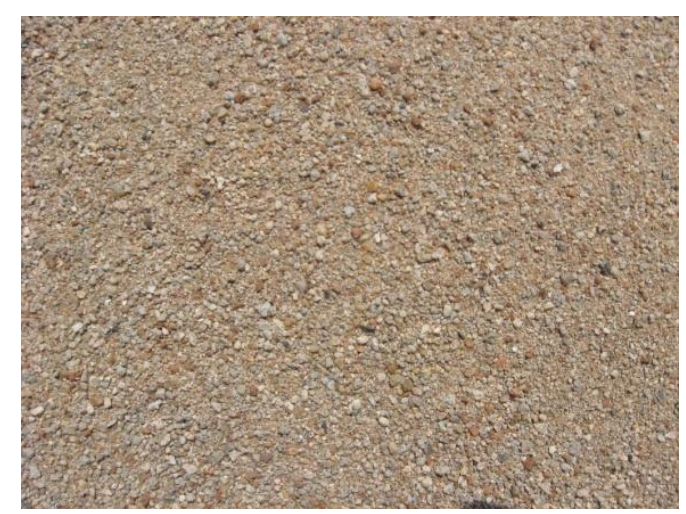

\section{Recycled Aggregate}

Uses

- To provide excellent acceleration of strength gain at early ages and major increases in strength at all ages by significantly reducing water demand in a concrete mix.

- Particularly suitable for precast concrete and other high early strength requirements.

- To significantly improve the workability of site mixed and precast concrete without increasing water demand. 
- To provide improved durability by increasing ultimate strengths and reducing concrete permeability.

- In screeds it reduces the water content required to give suitable workability for placing and compaction.

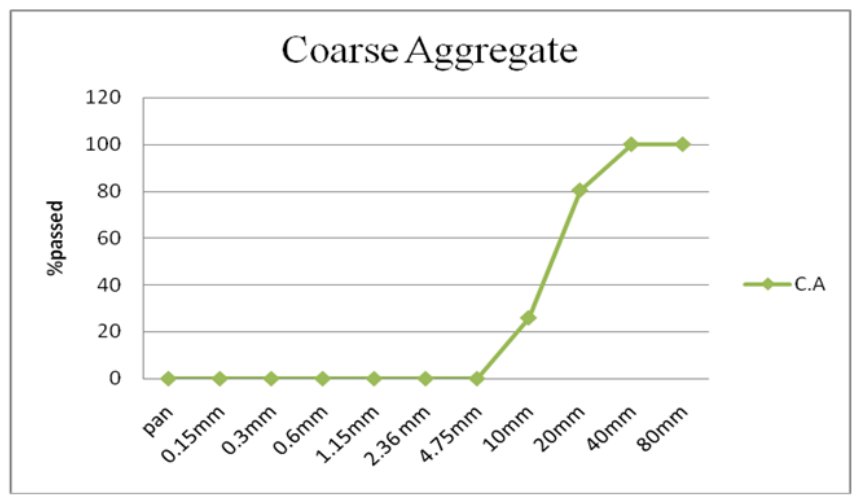

Graph 3.1

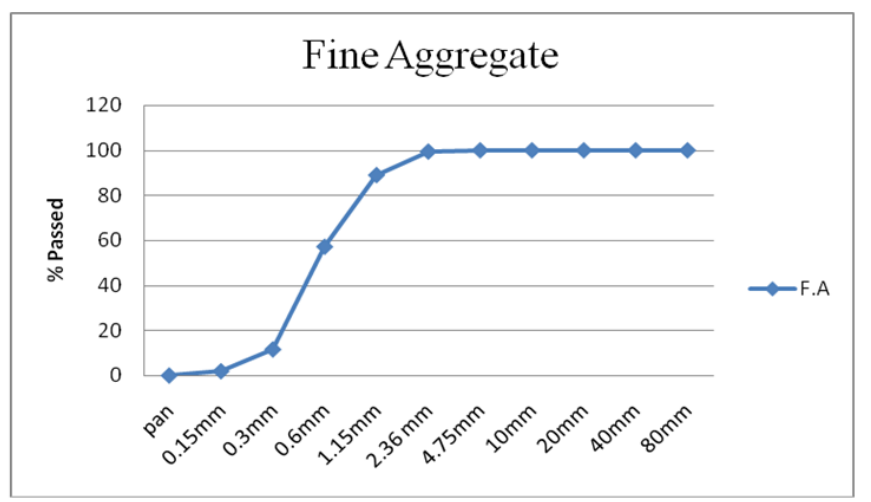

Graph 3.2

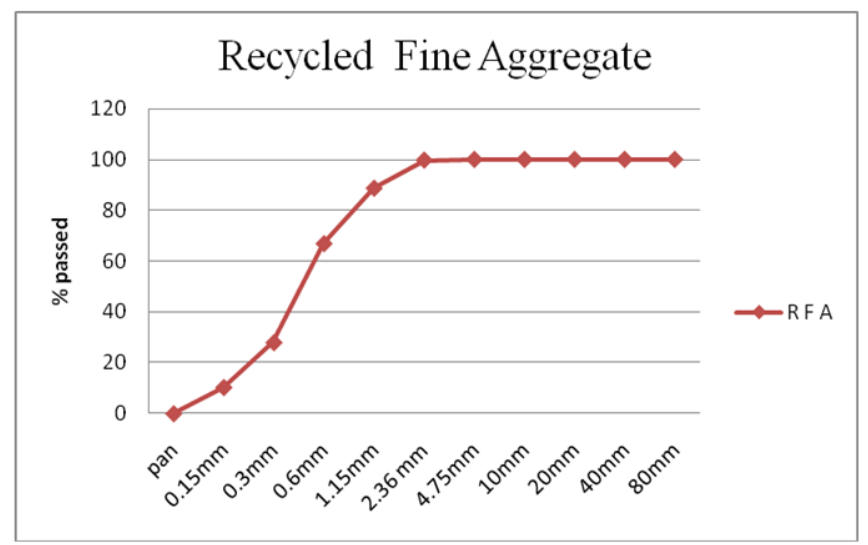

Graph 3.3

When we come across the graph that showing the comparison between sieve analysis of river sand and recycled fine aggregate, we can notice some important things. They are:

A. As it indicates that the river sand is lower than the RFA curve.

B. The presence of the percentage of fines is more in the RFA

C. When the fines are more in the aggregate that we use commonly the water absorption also increases

D. So, more water is to be used, as in this study we had got the water absorption percentage as $4 \%$.

E. Similarly, we can notice the increase in the density and specific gravity of the RFA than the normal sand.

\subsection{Mix proportioning}

There are various methods of mix proportioning. Mix proportioning was based on the water cement ratio (water/cement) and the density of the concrete is $2400 \mathrm{~kg} / \mathrm{m}^{3}$. Quantity of water is taken according to slump of concrete 0.5 for economical purpose. The quantity of cement i.e; $350 \mathrm{~kg} / \mathrm{m}^{3}$ used. Therefore, quantity of water should be $175 \mathrm{~kg} / \mathrm{m}^{3}$. For fine and coarse aggregate absorption of water in additional $1 \%$ and $0.8 \%$ of water was used. The quantity of aggregates is taken based on the aggregate grading curve is selected. The quantity of fine aggregates used is $646 \mathrm{~kg} / \mathrm{m}^{3}$, coarse aggregates is $1229 \mathrm{~kg} / \mathrm{m}^{3}$, the quantity of $20 \mathrm{~mm}$ and $12 \mathrm{~mm}$ are $502 \mathrm{~kg} / \mathrm{m}^{3}$ and $727 \mathrm{~kg} / \mathrm{m}^{3}$.

For the investigation purpose the fine aggregates replaced with recycled fine aggregates in percentage relatively $0,20,50,80$ and 100 percent for the mixes $\mathrm{M}_{1}, \mathrm{M} 2, \mathrm{M} 3, \mathrm{M} 4$ and $\mathrm{M}_{5}$ respectively.

\subsection{Specimen Details}

The specimens like cubes, cylinders and beams that are used to conduct the strength tests are taken according to IS10086-1982.

Compression strength $=$ cube moulds of $150 \mathrm{mmX} 150 \mathrm{mmX} 150 \mathrm{~mm}$ are used. 
Split tensile strength $=$ cylindrical moulds of 100dia@200mm height are used.

\subsection{Curing procedure}

After casting the cubes and cylinders the specimens were left for 24 hours then they remoulded and kept in normal water curing. The specimens were kept for normal water curing until testing age

\section{STRENGTH PROPERTIES}

This chapter explains about the strength properties like compressive strength and split tensile strength.

\subsection{Testing of Compressive Strength:}

Compression test is done confirming to IS: 516-1953. All the concrete specimens that are tested in a 2000KN capacity Compressive-testing machine. Concrete cubes of size $150 \mathrm{~mm} \times 150 \mathrm{~mm} \times 150 \mathrm{~mm}$ and cylinders of size $100 \mathrm{~mm}$ dia \& $200 \mathrm{~mm}$ height were tested for crushing strength, crushing strength of

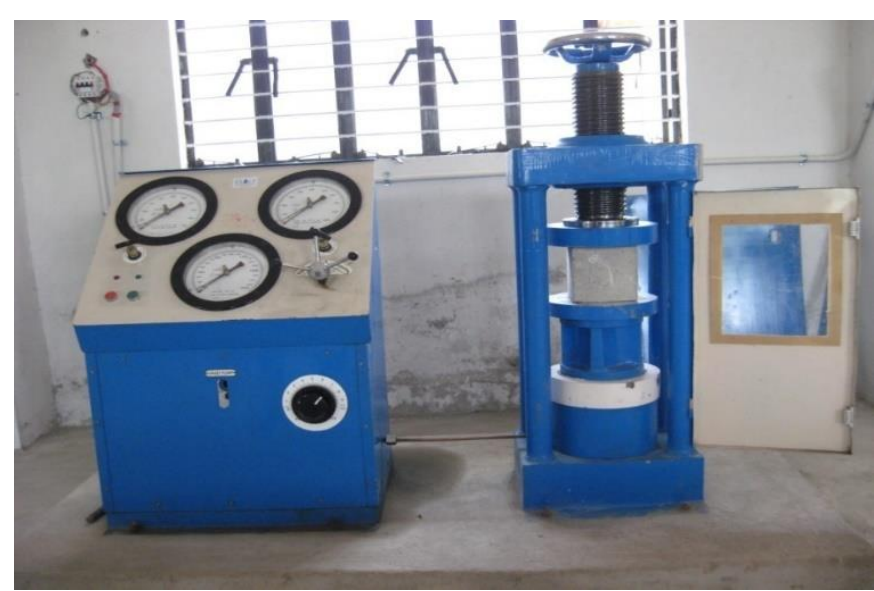

4.1.3 Compressive Strength of different mixes

\begin{tabular}{|c|c|c|c|}
\hline \multicolumn{4}{|c|}{ Compressive strength $\mathrm{N} / \mathrm{mm}^{2}$} \\
\hline Mix & 3days & 7 days & 28 days \\
\hline M1 & 12.15 & 24.30 & 32.40 \\
\hline M2 & 13.48 & 26.96 & 35.95 \\
\hline M3 & 13.10 & 26.22 & 34.96 \\
\hline M4 & 12.00 & 24.00 & 32.00 \\
\hline M5 & 8.67 & 17.33 & 23.11 \\
\hline
\end{tabular}
concrete was determined by applying load at the rate of $1400 \mathrm{~N} / \mathrm{cm}^{2} / \mathrm{min}$ till the specimens fail. The maximum load applied to the specimens was recorded and divided the failure load with crosssectional area of the specimens for compressive strength has been calculated.

Compressive strength test was conducted on cubes of $150 \mathrm{mmX} 150 \mathrm{mmX} 150 \mathrm{~mm}$ cubes for the various mixes M1,M2,M3,M4 and M5 of the Recycled fine aggregate concrete are given in the below table

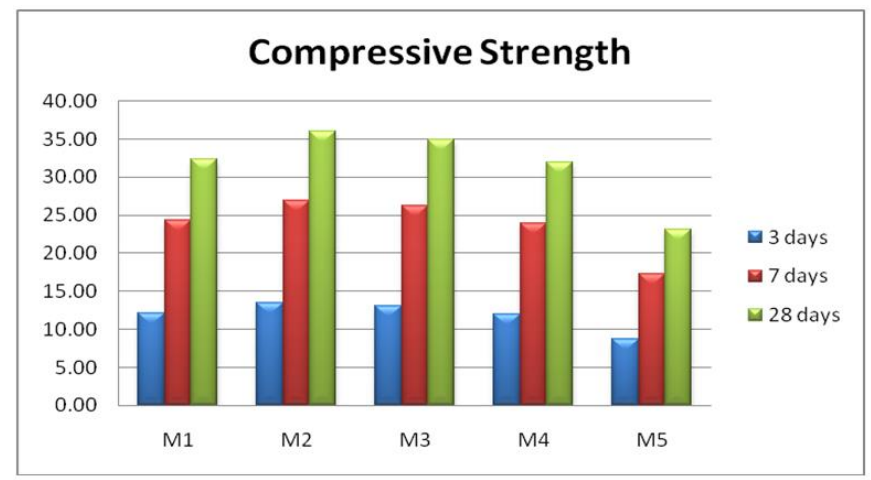

- The cube compressive strength results at 3, 7 and days with various percentage replacement of the fine aggregate by recycled fine aggregate at 0,20 , 50,80 and 100 percentages are shown in the table 4.3.

- Compressive strength of the cubes at the 3 days is varied from one mix to the other, from $0 \%$ to 20 $\%$ replacement of the fine aggregate the strength has been increased from $12.15 \mathrm{mpa}$ to $13.48 \mathrm{mpa}$. The strength had been decreased when the 
percentage of the aggregate replacement is increased. When it has increased from $20 \%$ to $50 \%$ then strength decreased from 13.48 to 13.10 . Similarly for the next proportions the strength reduced as 12 and 8.67 for $80 \%$ and $100 \%$ replacement respectively.

- Compressive strength of 7 days is varied from one mix to the other, from $0 \%$ to $20 \%$ replacement of the fine aggregate the strength has been increased from $24.30 \mathrm{mpa}$ to $26.96 \mathrm{mpa}$. The strength had been decreased when the percentage of the aggregate replacement is increased. When it has increased from $20 \%$ to $50 \%$ then strength decreased from26.96 to 26.22. Similarly for the next proportions the strength reduced as 24 and 17.33 for $80 \%$ and $100 \%$ replacement respectively.

- The same has been repeated in the 28 days strength results, but the results that are shown in the 28 days are more than the target strength of the M20 grade. As the results shown in the table 4.1 the strengths of 28 days for the mixes M1, M2, M3, M4 and M5 are 32.4, 35.95, 34.96, 32 and $23.11 \mathrm{~N} / \mathrm{mm} 2$ respectively.

- So we can make the replacement of the fine aggregate with the construction waste and the demolition waste. The replacement can not be done $100 \%$ as the strength parameters may have a large difference in comparison with natural aggregates.

\subsection{Split Tensile Strength}

This test is conducted in a $2000 \mathrm{KN}$ capacity Compression-testing machine by placing the cylindrical specimen, so that its axis is horizontal to the plates of the testing machine. Narrow strips of packing material i.e., plywood is placed between the plates and the cylinder to receive compressive stress. The load was applied uniformly at a constant rate until failure by splitting along the vertical axis takes place. Load at which the specimens failed is recorded and the split tensile stress is obtained using the formula based on IS: 5816-1970.

$$
F_{t}=2 P / \pi D L
$$

Where $\mathrm{P}=$ Compressive load on the cylinder

$\mathrm{L}=$ Length of the cylinder $\mathrm{D}=$ Diameter of the cylinder

Split tensile strength has done for the mixes M1, M2, M3, M4 and M5 of the recycled fine aggregate concrete the test has conducted on the cylinder of $100 \mathrm{mmX} 200 \mathrm{~mm}$. The values of the split tensile strength test at the age of 1 day, 7 days, 28 days has shown in the table below

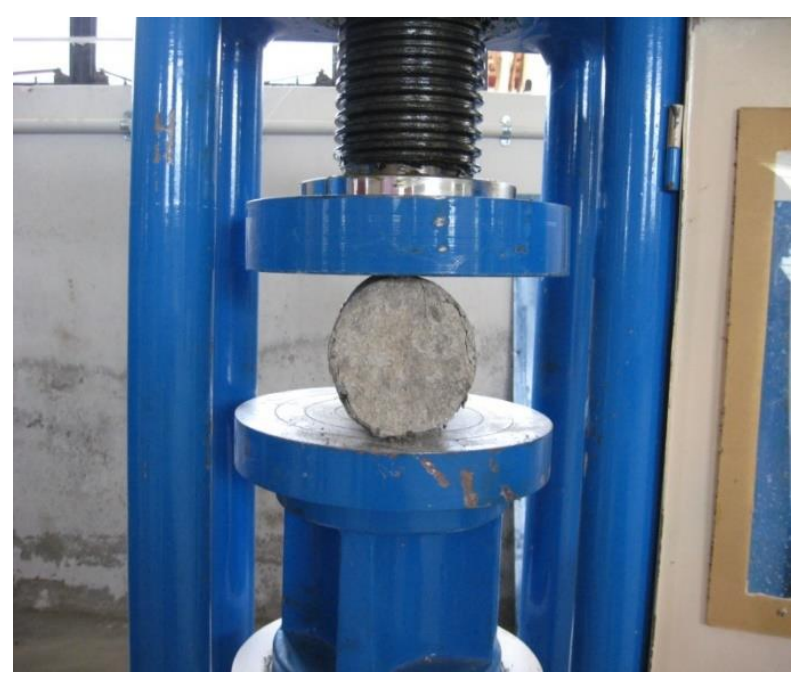

\subsubsection{Split Tensile Strength for different mixes}

\begin{tabular}{|l|r|r|r|}
\hline \multicolumn{4}{|c|}{ Split Tensile Strength N/mm ${ }^{2}$} \\
\hline Mix & \multicolumn{1}{|c|}{ 3 days } & \multicolumn{1}{c|}{ 7 days } & \multicolumn{1}{l|}{ 28 days } \\
\hline M1 & 1.49 & 2.33 & 2.52 \\
\hline M2 & 1.53 & 2.34 & 2.60 \\
\hline M3 & 1.59 & 2.36 & 2.65 \\
\hline M4 & 1.19 & 2.22 & 2.41 \\
\hline M5 & 0.88 & 2.22 & 2.33 \\
\hline
\end{tabular}

Table 4.6 


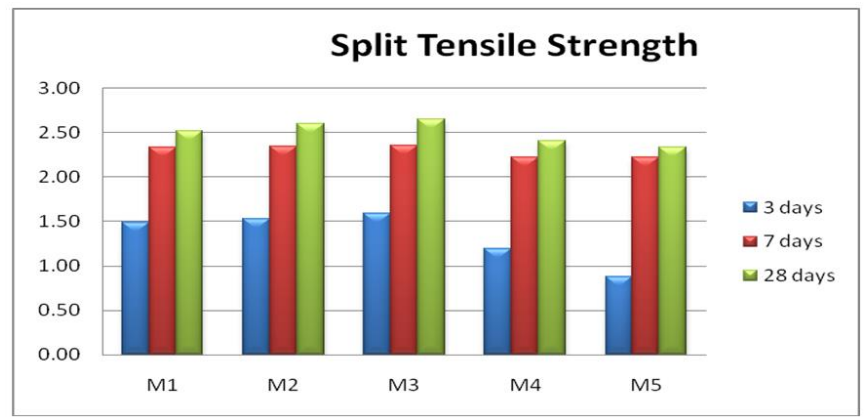

Graph 4.2 Age vs split tensile strength

Split Tensile test is conducted on the cylinders of the sizes in ratio $1: 2$ to the diameter and length of the specimen. In this investigation totally 36 cylindrical moulds of size $100 \mathrm{~mm}^{*} 200 \mathrm{~mm}$ were tested for knowing Split tensile strength of different mixes at 3 days , 7days, and 28 days.

Split Tensile strength of the cubes at the 3 days is varied from one mix to the other, from $0 \%$ to $20 \%$ replacement of the fine aggregate the strength has been increased from $1.49 \mathrm{mpa}$ to $1.53 \mathrm{mpa}$. The strength had been decreased when the percentage of the aggregate replacement is increased. When it has increased from $50 \%$ to $80 \%$ then strength decreased from 1.59 to 1.19 . Similarly for the next proportion the strength reduced to $0.88 \mathrm{~N} / \mathrm{mm}^{2}$.

Split Tensile strength of 7 days is varied from one mix to the other, from $0 \%$ to $20 \%$ replacement of the fine aggregate the strength has been increased from 2.33 mpa to $2.34 \mathrm{mpa}$. The strength had been decreased when the percentage of the aggregate replacement is increased. When it has increased from $50 \%$ to $80 \%$ then strength decreased from2.36 to 2.22. Similarly for the next proportion the strength reduced to 2.22

The same has been repeated in the 28 days strength results, but the results that are shown in the 28 days are more than the target strength of the M20 grade. As the results shown in the table 4.1 the strengths of
28 days for the mixes M1, M2, M3, M4 and M5 are $2.52,2.60,2.65,2.41$ and $2.33 \mathrm{~N} / \mathrm{mm}^{2}$ respectively.

The targeted strength is not fixed for the split tensile strength but the tensile strength should reach $10 \%$ of the compressive strength and in our investigation we could not achieve the tensile property.

So we can make an note that the tensile property of the concrete is decreased with usage of the recycled fine aggregate in large proportions.

\section{IV.TRANSPORT PROPERTIES}

Various spermous properties of recycled fine aggregate concrete has tested for the different mixes. The properties that tested for the recycled fine aggregate concrete are mentioned below.

\section{Evaporation test.}

2. Absorption test.

3. Moisture migration test.

\subsection{Evaporation test}

Evaporation test has done on the cubes of $150 \mathrm{~mm} x 150 \mathrm{mmx} 150 \mathrm{~mm}$ for the mixes of recycled fine aggregate concrete. It has done after curing of 28 days. After curing of 28 days cube specimens were allowed to normal temperature to normal dry, after normal drying cube specimens were kept in oven at the temperature of $95^{\circ} \mathrm{C}$ cube specimens were taken from the oven at ages of 15mins, 30mins, 1hour, 2hours, 3hours, 4hours, 24hours, 48hours, 72hours. The values of percentages of evaporation at the ages of 15mins, 30mins, 1hour, 2hours, 3hours, 4hours, 24hours, 48hours, and 72hours. 
The values of percentages of evaporation at the ages of 15mins, 30mins, 1hour, 2hours, 3hours, 4hours, 24hours, 48hours, and 72hours are given below in the table 5.2 and this are obtained from the observations that are made from the investigation by taking the changes in the weights of the specimens in periodical ages.

As we had conducted some physical test on the materials and found that the water absorption of RFA as $4 \%$ for the different mix proportions of the fine aggregate replacement there will be change in the water/cement ratio.

Graph 5.1 represents the variations of the percentage evaporation occurred in different ages for the different mixes. The evaporation in the early stages is very high and later it decreases. At the age of 24 hours the evaporation has been continuously decreased from the mix M1 to M4 as 4.69 to 3.2 and in M5 mix it has increased to 4.56percent. The evaporation is majorly depended on the properties of the ingredients that are used in the concrete as the fines present in the aggregates are more then the absorption is more and that will affect the evaporation property.

Generally the water absorption of the recycled materials will be $4 \%$ to $8 \%$. In our investigation we got water absorption as $4 \%$. So the absorption we got is optimum and that may not affect the properties of the concrete.

By this we can notice that there is no much variation in the water evaporation in the different mix proportions of the recycled aggregate as a replacement. As there is no large variation between the percentages evaporation that had been made in the results, so we can make a statement that recycled fine aggregate does not make any abnormal change in the transport properties.

The results that are observed in the evaporation test are constant and we can make a statement that replacement of the fine aggregates with the construction and demolition waste does make any changes in the durability properties

\subsection{Water Absorption test}

Water Absorption test has done on the cubes of $150 \mathrm{mmx} 150 \mathrm{mmx} 150 \mathrm{~mm}$ for the mixes of recycled fine aggregate concrete. It has done after 72 hours evaporation cube specimen. After 72hours evaporation cube specimens were allowed to normal temperature, cube specimens were kept in curing tank and the weight of the specimen are taken at the ages of 15mins ,30mins, 1hour, 2hours, 3hours, 4hours, 24hours, 48hours, 72hours and percentage absorption is calculated. The values of percentages of absorption at the ages of $15 \mathrm{mins}, 30 \mathrm{mins}, 1$ hour, 2hours, 3hours, 4hours, 24hours, 48hours and 72hours are given in table

\subsection{Moisture migration test}

Moisture migration test has done on the cubes of $150 \mathrm{mmx} 150 \mathrm{mmx} 150 \mathrm{~mm}$ for the mixes of recycled fine aggregate concrete. It has done after 72 hours evaporation, cube specimens were allowed dry to normal temperature. Cube specimens were kept on the layer of water for the absorption of moisture, cube specimens were taken from the moisture migration test at the ages of $15 \mathrm{mins}, 30 \mathrm{mins}$, 1hour, 2hours, 3hours, 4hours, 24hours, 48hours and 72hours. The values of moisture migration in $\mathrm{mm}$ are noted and the percentages of moisture migration at the ages of $15 \mathrm{mins}, 30 \mathrm{mins}, 1$ hour, 2hours, 3hours, 
4hours, 24hours, 48hours and 72hours are calculated. The values are given below in the table.

\section{CONCLUSION}

Results of experiments on compressive strength, split tensile strength, water absorption and evaporation for different recycled fine aggregate concrete have been presented with those of control concrete. For the mixes of the replaced aggregate with the construction waste the investigation had been made on different strength and transport properties and the following conclusions are made

- In the recycled aggregate the percentage of fines present is more than that of the natural sand.

- As the fines are more then the water absorption also increases. The absorption of RFA is $4 \%$.

- The RFA does affect the fresh properties of the concrete.

- The compressive strength is increased up to some percentage of the replacement.

- The properties of the recycled fine aggregate are very similar to the natural aggregates.

- The recycled fine aggregates gives a dense concrete as the fines help in making.

- Tensile strength of the concrete also increases in the replacement of the fine aggregate only up to some percentage.

- This recycling has lots of advantages to the environment and human kind.

- So the replacement of the fine aggregate in the concrete can be done by the construction and demonization waste.

\section{REFERENCES}

[1]. Gambhir M.L, "Concrete Manual”, Dhanpat Rai \& Co. (Pvt) Ltd., Educational and Technical Publishers, 1710, Nai Sarak, New Delhi-110 006.
[2]. Sheety M.S, "Concrete Technology", S.Chand \& Company Ltd., Ram Nagar, New Delhi-110 055.

[3]. I.S 456 (2000), "Indian Standard code of practice for plain and reinforced concrete", Fourth revision, Bureau of Indian standards, Manak Bhavan, 9 Bahadur Shah Zafar Marg, New Delhi-110 002, India.

[4]. I.S 10262 (1982), "Recommended guidelines for concrete mix design", IFrst revision, Bureau of Indian standard, Manak Bhavan, 9 Bahadur Shah Zafar Marg, New Delhi-110 002, India.

[5]. I.S 10262 (2009), "Concrete mix proportioning ", First revision, Bur-Guidelineseau of Indian standard, Manak Bhavan, 9 Bahadur Shah Zafar Marg, New Delhi-110 002, India.

\section{Cite this article as :}

B. Srinivasulu, K. Mohammed Rasheed, "An Experimental Investigation on The Properties of Concrete by Partial Replacement of Fine Aggregate with Demolition Waste", International Journal of Scientific Research in Science and Technology (IJSRST), Online ISSN : 2395-602X, Print ISSN : 2395-6011, Volume 6 Issue 2, pp. 624-633, MarchApril 2019. Available at doi : https://doi.org/10.32628/IJSRST1962136 Journal URL : http://ijsrst.com/IJSRST1962136 